\title{
A APRENDIZAGEM INSTRUMENTAL SOB A PERSPECTIVA DA AUTORREGULAÇÃO: CONTRIBUIÇÕES DE UM ESTUDO DE CASO
}

\author{
The instrumental learning from the self- \\ regulation perspective: contributions from a \\ case study
}

\author{
Aprendizaje instrumental desde la \\ perspectiva de la autorregulación: \\ contribuciones de un estudio de caso
}

\author{
Flávio Denis Dias Veloso \\ Pontifícia Universidade Católica do Paraná / Universidade Estadual do Paraná \\ flavio.d.veloso@hotmail.com \\ RosAnE CARDOSO DE ARAÚJO \\ Universidade Federal do Paraná (UFPR) \\ rosane_caraujo@yahoo.com.br
}

\begin{abstract}
Resumo: O escopo deste artigo é apresentar parte dos resultados de uma pesquisa que abordou a autorregulação da aprendizagem instrumental sob a perspectiva sociocognitiva. Nesta abordagem, a autorregulação consiste em intervir de forma consciente, intencional e autorreflexiva no próprio desenvolvimento, considerando os aspectos comportamentais, motivacionais, cognitivos e metacognitivos da aprendizagem musical. O objetivo desta pesquisa foi investigar - por meio de um estudo de caso - elementos da autorregulação na conduta de uma percussionista durante o aprendizado de uma nova obra musical. Os resultados apontaram a ocorrência de eventos relativos ao planejamento (delineamento das metas; pensamento antecipatório; planificação das tarefas), monitoramento (experiências metacognitivas; observação e interpretação dos desafios; revisão de metas e estratégias) e avaliação da aprendizagem (atribuições causais; inferências autoavaliativas e autorreativas). Esperamos que as considerações aqui apresentadas favoreçam o aprimoramento de condutas que orientem a prática musical de estudantes em direção ao desenvolvimento musical reflexivo e autônomo.
\end{abstract}

Palavras-chave: Aprendizagem instrumental. Autorregulação. Metacognição. Teoria social cognitiva.

Abstract: The aim of this paper is to present part of the results of a research based on the self-regulation of instrumental learning from a sociocognitive perspective. In this approach, self-regulation consists of conscious, intentional and self-reflexive intervention in one's own development, considering the behavioral, motivational, cognitive and metacognitive aspects of musical learning. The objective of this research was to investigate - through a case study - elements of self-regulation in the conduct of a percussionist during the learning of a new musical piece. The results highlighted here indicate the occurrence of events related to planning (goal setting; anticipatory thinking; task planning), monitoring (metacognitive experiences; observation and interpretation of challenges; revision of goals and strategies) and evaluation of learning (causal attributions; self-evaluating and self-reactive inferences). We hope that the considerations presented here favor the improvement of conducts that guide the musical practice of students towards the reflexive and autonomous musical development.

Keywords: Instrumental learning. Self-regulation. Metacognition. Social cognitive theory.

Resumen: El enfoque de este artículo es presentar parte de los resultados de una investigación que abordó la autorregulación del aprendizaje instrumental desde la perspectiva sociocognitiva. En este enfoque, la autorregulación consiste en intervenir consciente, intencional y autorreflexivamente en el propio desarrollo, considerando los aspectos conductuales, motivacionales, cognitivos y metacognitivos del aprendizaje musical. El objetivo de esta investigación fue investigar, a través de un estudio de caso, elementos de autorregulación en la conducta de un percusionista durante el aprendizaje de una nueva obra musical. Los resultados indicaron la ocurrencia de eventos relacionados con la planificación (establecimiento de objetivos; pensamiento anticipado; planificación de tareas), monitoreo (experiencias metacognitivas; observación e interpretación de desafios; revisión de objetivos y estrategias) y evaluación del aprendizaje (atribuciones causales; inferencias evaluativas y autorreactivas). Esperamos que las consideraciones presentadas aquí favorezcan la mejora de los comportamientos que guian la práctica musical de los estudiantes hacia el desarrollo musical reflexivo y autónomo.

Palabras clave: Aprendizaje instrumental. Autorregulación. Metacognición. Teoría social cognitiva. 


\section{INTRODUÇÃO}

O êxito na prática instrumental requer o desenvolvimento e a aplicação de diferentes estratégias de estudo, a manutenção dos fatores motivacionais que garantirão o envolvimento com as tarefas, o gerenciamento e a criação das condições ambientais favoráveis à aprendizagem, a capacidade de planejar, monitorar e avaliar o próprio desempenho, dentre outros fatores que favorecem o protagonismo dos estudantes em seu desenvolvimento (McPherson et al., 2013). Neste cenário, destaca-se a autorregulação da aprendizagem, que diz respeito aos mecanismos que as pessoas usam para dirigir o próprio desenvolvimento, a partir do delineamento de objetivos e diretrizes de estudo, e utilizando estratégias de planejamento, monitoramento e avaliação dos pensamentos, sentimentos e ações, visando à realização de mudanças autodirecionadas (Bandura, 1991; Azzi et al., 2016, p. 107).

O estudo autorregulado inclui a mobilização de mecanismos cognitivos e metacognitivos, a exemplo do estabelecimento de metas, o automonitoramento, a autorreflexão, a autoavaliação, as iniciativas autorreativas e as crenças de autoeficácia - compreendidas como a percepção pessoal em relação à própria inteligência, às habilidades, aos conhecimentos e aos recursos que se dispõem para a realização de determinada tarefa (Schunk, 2015, p. 63). Conforme sugere Cavalcanti (2015, p. 196), em situações desafiadoras para musicistas (como a preparação de repertórios de elevado grau de dificuldade ou situações de avaliação), alunos, com baixas crenças de autoeficácia em sua capacidade para autorregular seus estudos, podem apresentar um desempenho inferior às suas potencialidades.

Partindo do exposto, a problemática que orientou a realização desta investigação considerou a seguinte questão: como os percussionistas ${ }^{1} \mathrm{em}$ formação autorregulam o estudo no confronto com a preparação de uma nova obra musical? Assim, foi definido o seguinte objetivo geral: investigar, por meio de um estudo de caso, elementos da autorregulação da aprendizagem na conduta de uma percussionista durante o estudo de uma obra musical. O objetivo geral foi alcançado por meio de diferentes objetivos específicos, dentre os quais destacamos para nortear o presente artigo: "observar a ocorrência de eventos relativos ao planejamento, monitoramento e avaliação da aprendizagem". ${ }^{2}$

\footnotetext{
${ }^{1}$ Uma descrição detalhada a respeito da aprendizagem instrumental de percussionistas (bem como as justificativas para a adoção deste objeto de estudo na presente investigação) pode ser consultada na dissertação que deu origem a este artigo (Veloso, 2019).

${ }^{2}$ Os demais objetivos específicos não contemplados no presente recorte foram: investigar os aspectos motivacionais que exerceram influência no processo de estudo da peça; averiguar "quais" e "como" foram empregadas as estratégias cognitivas e metacognitivas de aprendizagem; verificar o impacto das variáveis ambientais no processo de aprendizagem.
} 
Os estudos que relacionam o desenvolvimento de instrumentistas com condutas autorregulatórias têm despertado o interesse de pesquisadores das áreas da performance, cognição e educação musical, revelando um profícuo campo de investigação. Não obstante, nota-se "uma lacuna teórica a respeito dos comportamentos autorreguladores em músicos profissionais e naqueles que se preparam para tal carreira" (Araújo, 2015, p. 146). Além disso, a ênfase nos aspectos qualitativos da prática instrumental ainda é recente nos estudos sobre performance musical no Brasil, havendo a necessidade de ampliação das pesquisas neste campo. Portanto, pretende-se com esta pesquisa propor reflexões à luz da autorregulação sob a perspectiva da teoria social cognitiva, considerando que "seu aporte favorece a construção de um amplo cenário de investigação e discussão em direção a melhoria da aprendizagem, performance e ensino no campo musical” (Azzi, 2015, p. 16).

\section{A AUTORREGULAÇÃO SOB O PRISMA SOCIOCOGNITIVO}

A concepção de autorregulação aqui preconizada apoia-se no aporte oferecido pela teoria social cognitiva (TSC), "uma perspectiva em psicologia formulada pelo psicólogo Albert Bandura, inicialmente uma teoria de aprendizagem que foi se ampliando para configurar-se em uma teoria geral em psicologia que objetiva explicar o comportamento e desenvolvimento humanos" (Bandura, 1986 apud Azzi, 2015, p. 10). Esta teoria busca descrever os indivíduos como agentes humanos, capazes de mobilizar fatores cognitivos, afetivos e comportamentais em interação com o ambiente e a própria conduta, influenciando seu desenvolvimento de maneira intencional.

Nesta pesquisa, a adoção da TSC deu-se (dentre outros fatores) por esta teoria comportar um amplo entendimento dos processos de autorregulação da ação, cognição e emoção. Bandura (1991, p. 249) esclarece que a autorregulação opera por meio de três subfunções psicológicas que devem ser desenvolvidas para promover êxitos nas realizações pessoais, a saber: auto-observação, autojulgamento e autorreação. Estas subfunções guardam uma relação dinâmica de interação, possibilitando que, "enquanto alguém observa seu próprio comportamento [auto-observação], já poderá o estar comparando com seus padrões de referência pessoais [autoavaliação] e reagindo positiva ou negativamente [autorreação]" (Azzi, 2015, p. 12; grifo nosso). 

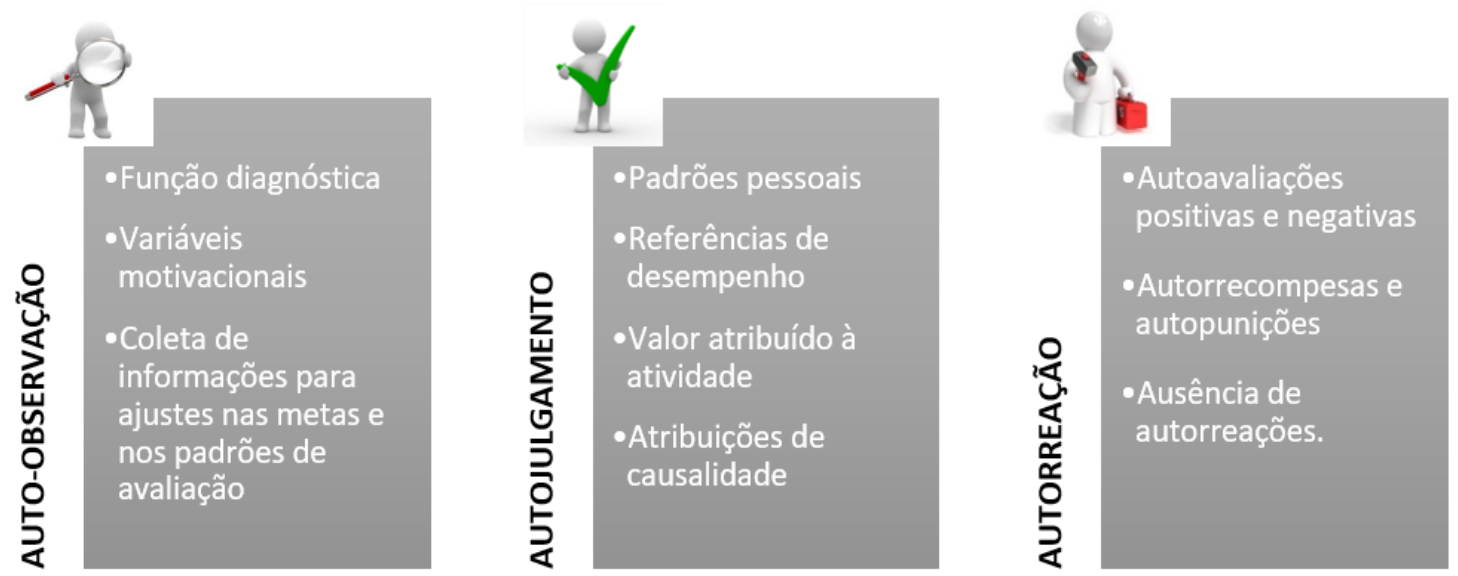

Figura 1: Subfunções da autorregulação. Baseado em Bandura (1991, p. 249).

Visando à sistematização das dimensões e subprocessos da autorregulação, estudiosos têm trabalhado na construção de modelos de investigação e intervenção educacional. As propostas que assumem a TSC como orientação epistemológica baseiam-se nas subfunções psicológicas apresentadas por Bandura e nas dimensões comportamental, motivacional, afetiva, cognitiva e metacognitiva dos processos autorregulatórios. Nesse caminho, Zimmerman e Risemberg (1997) propuseram a Abordagem Multidimensional da Autorregulação da Aprendizagem, que permite uma compreensão mais abrangente da autorregulação, atentando para suas dimensões e componentes. A adoção desta perspectiva no campo musical é particularmente interessante, uma vez que auxilia na compreensão dos processos-chave envolvidos no desenvolvimento da expertise instrumental (McPherson et al., 2013).

\begin{tabular}{|c|c|c|c|c|c|}
\hline \multicolumn{5}{|c|}{$\begin{array}{c}\text { Dimensões e processos subjacentes à } \\
\text { “Abordagem Multidimensional da Autorregulação da Aprendizagem” }\end{array}$} \\
\hline Motivação & Método & Tempo & Desempenho & $\begin{array}{c}\text { Ambiente } \\
\text { físico }\end{array}$ & $\begin{array}{c}\text { Influências } \\
\text { sociais }\end{array}$ \\
\hline $\begin{array}{c}\text { Autoeficácia, } \\
\text { metas e }\end{array}$ & $\begin{array}{c}\text { Elaboração } \\
\text { e emprego } \\
\text { expectativas } \\
\text { de resultado. }\end{array}$ & $\begin{array}{c}\text { Gestão } \\
\text { temporal no } \\
\text { planejamento } \\
\text { e realizações }\end{array}$ & $\begin{array}{c}\text { Planejamento, } \\
\text { monitoramento } \\
\text { avaliação da } \\
\text { aprendizagem }\end{array}$ & $\begin{array}{c}\text { Estruturação } \\
\text { ambiental: } \\
\text { seleção de } \\
\text { recursos. }\end{array}$ & $\begin{array}{c}\text { Manutenção } \\
\text { das fontes } \\
\text { de apoio } \\
\text { social }\end{array}$ \\
\hline
\end{tabular}

Figura 2: Abordagem Multidimensional da Autorregulação da Aprendizagem - dimensões e processos. Adaptado de McPherson e colaboradores (2013, p. 359).

Embora os resultados desta pesquisa contemplem as seis dimensões da autorregulação (Figura 2), o recorte delimitado para este texto concentra-se na dimensão "desempenho", mais especificamente na regulação 
metacognitiva, que opera por meio de três processos centrais: ${ }^{3}$ planejamento, monitoramento e avaliação dos pensamentos e ações mobilizadas em determinadas realizações (Flavell, 1979; Cambridge, 2017). Estes processos estão ligados “à vigilância daquilo que se faz, à verificação de progressos e à avaliação da conformidade e da pertinência das etapas seguidas, dos resultados obtidos ou das estratégias utilizadas" (Lafortune; Santi-Pierre, 1996 apud Portilho; Dreher, 2012, p. 186).
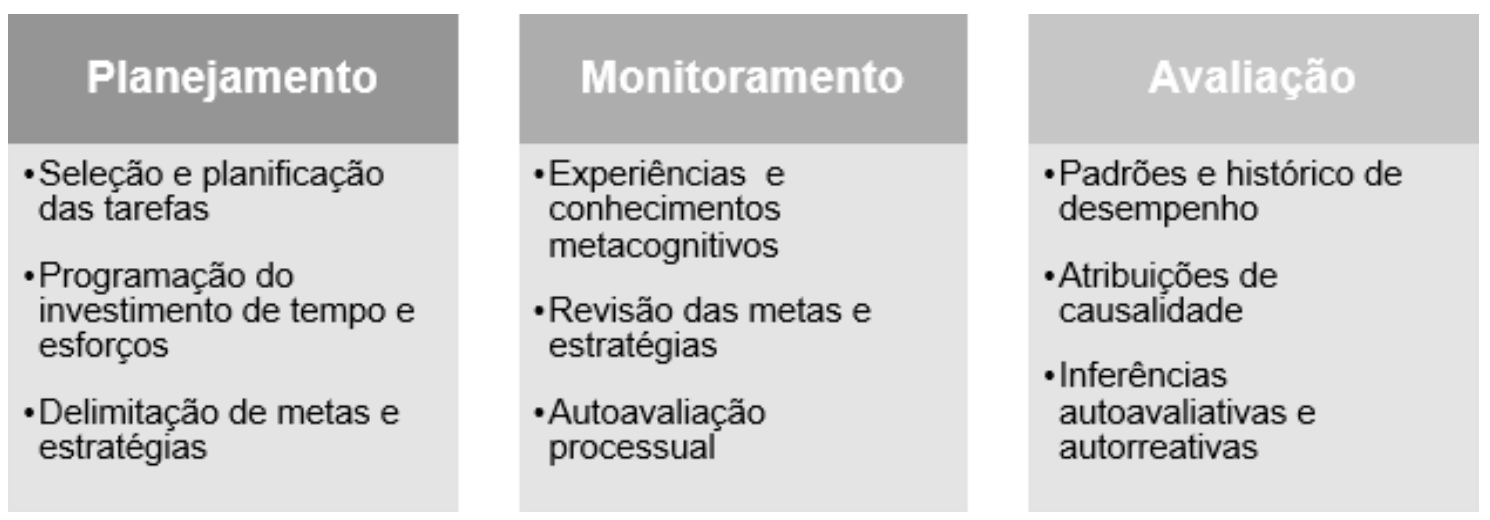

Figura 3: Fases da autorregulação metacognitiva. Baseado em Flavell (1979).

\section{ABORDAGEM METODOLÓGICA: O ESTUDO DE CASO}

O método aqui adotado foi o estudo de caso descritivo (Yin, 2005), assumindo como unidade de análise o processo de estudo de uma obra musical - Variantes $^{4}$ (1962), para percussão-múltipla solo (Leo Brouwer, 1939) -, empreendido por uma aluna de graduação durante dois meses e meio. A figura a seguir expõe as etapas e procedimentos deste estudo de caso, a partir das seguintes fases: definição do caso; coletado de dados; seleção, análise e interpretação.

\footnotetext{
3 "O fato de esses processos se descreverem em uma sequência linear de três fases não significa que toda a tarefa de aprendizagem ou de solução de problemas implique necessariamente da mesma maneira os três tipos de processos, nem tampouco que se apliquem sempre nessa ordem, já que em muitos casos eles interagem de forma complexa, influenciando-se uns aos outros. Os processos de controle são processos mais recorrentes do que lineares" (Mateos, 2001 apud Portilho; Dreher, 2012, p. 187).

${ }^{4}$ Uma descrição da obra Variantes (1962) pode ser consultada em Veloso (2019, p. 91).
} 


\section{Desenho metodológico - fases e procedimentos da pesquisa} 1. Definição do
caso

\section{Seleção, análise e interpretação}

\section{Caso "Ana":}

Percussionista graduanda ${ }^{1}$ no $1^{\circ}$ ano de bacharelado em instrumento em uma IES pública de Curitiba, Paraná, Brasil.

\section{Coleta de dados}

\section{Entrevistas \\ Semiestruturadas ${ }^{2}$ : \\ Uma entrevista prévia + quatro de periodicidade quinzenal durante dois meses e meio (período de estudo da obra). Todas as entrevistas \\ foram baseadas em roteiros predefinidos.}

$\begin{array}{cc}\text { Entrevista } & \text { Entrevistas } \\ \text { prévia: } & \text { quinzenais: } \\ \text { Ênfase na } & \text { Ênfase em } \\ \text { descrição do } & \text { aspectos da } \\ \text { perfil da } & \text { preparação da } \\ \text { aluna, nos } & \text { obra como as } \\ \text { aspectos } & \text { estratégias, } \\ \text { formativos, } & \text { planejamento, } \\ \text { experiências } & \text { observação e } \\ \text { musicais e } & \text { avaliação das } \\ \text { hábitos de } & \text { sesső́es de } \\ \text { estudo. } & \text { prática. }\end{array}$

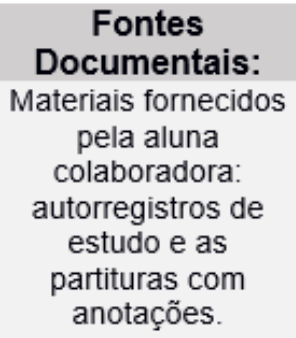

Fontes

Documentais:

Materiais fornecidos pela aluna colaboradora:

autorregistros de estudo e as

partituras com anotações.

\section{Registro em} vídeo:

Gravação de uma sessão de estudo individual no último dos quatro encontros quinzenais.

\section{Questionário múltipla escolha:}

Questionário contendo 20 questões baseadas em uma escala likert em cinco pontos, com o objetivo de verificar o uso de estratégias metacognitivas nos hábitos de estudo da percussionista.
Atividades desenvolvidas ${ }^{3}$ :

A coleta dos dados foi realizada em cinco encontros ao longo de dois meses e meio.

\section{Deliberações -} Encontro inicial: Encaminhamentos éticos ${ }^{4}$; escolha da obra musical ${ }^{5}$; definição do cronograma de coleta de dados; entrega do questionário.

\section{Encontros} quinzenais:

Quatro encontros nos quais foram realizadas entrevistas, coleta de documentos e gravações.

\section{Seleção: \\ Consistiu na transcrição, tabulação e organização categorial das informações, favorecendo um aproveitamento integral das fontes.}

\section{Análise:}

O tratamento e interpretação dos dados foi conduzido por meio da "Análise de conteúdo", segundo Bardin (2011)

$1 \mathrm{O}$ interesse em colaborar com o estudo manifestado pela estudante e a indicação realizada pelo professor da classe de percussão foram os principais critérios para a escolha da participante.

2 Cada entrevista durou em média 45 minutos. O registro ocorreu por meio de gravações de áudio realizadas em um Notebook Lenovo Ideapad 320 utilizando o software "Gravador de Voz".

${ }^{3}$ A coleta de dados aconteceu simultaneamente com o processo de estudo da obra, entre a segunda metade do mês de abril e a primeira metade do mês de junho de 2018.

${ }^{4}$ No primeiro contato com a aluna foram oferecidos esclarecimentos gerais sobre o estudo, entregue uma carta-convite e coletada a assinatura em um termo de consentimento livre e esclarecido.

${ }^{5}$ Foi definida a obra Variantes (1962) para percussão-múltipla solo, de Leo Brouwer (1939-). A escolha baseou-se nas recomendações do professor responsável pela classe e nas intenções da aluna, visando contribuir com o seu engajamento no estudo.

Figura 4: Delineamento metodológico - fases e procedimentos deste estudo de caso. 
Após a seleção dos dados (organizados integralmente em um dossiê), foram conduzidas as análises que possibilitaram a descrição, a interpretação e a realização de inferências sobre o fenômeno investigado. A aplicação da "análise de conteúdo" (Bardin, 2011) mostrou-se adequada à proposta deste estudo, promovendo "a reinterpretação das mensagens, atingindo uma compreensão de seus significados num nível que vai além de uma leitura comum, sendo conduzida principalmente por descrições sistemáticas" (Ferigato; Freire, 2015, p. 117). Considerou-se as três fases que integram esta abordagem - análise prévia, exploração do material, interpretação e inferências (Bardin, 2011) - associadas à "categorização semântica" e à "triangulação dos dados" (Yin, 2005).

\section{APRESENTAÇÃO E DISCUSSÃO DOS DADOS}

Orientados pelo objetivo específico "observar a ocorrência de eventos relativos ao planejamento, monitoramento e avaliação da aprendizagem", buscaremos o enfoque nas iniciativas autorregulatórias adotadas pela estudante durante o preparo da performance ${ }^{5}$. Somente uma parcela dos dados desta pesquisa está sendo considerada neste artigo. A totalidade dos resultados pode ser consultada em Veloso (2019).

\section{"Eu tento fazer um 'plano de estudo'”: o planejamento da prática instrumental}

A prática instrumental na perspectiva da autorregulação considera o planejamento da aprendizagem a partir do estabelecimento de "o que" (tarefas), "como" (estratégias) e "quando" (metas) realizar. "Em geral, quando se apresenta um problema ou uma situação nova a enfrentar, as pessoas organizam um plano que possa guiar sua atividade cognitiva e assim regular a execução da tarefa" (Portilho, 2011, p. 121-122). A figura a seguir apresenta a categorização dos dados referentes à fase de planejamento, considerando os aspectos teóricos que se destacaram ao longo do processo de estudo.

\footnotetext{
${ }^{5}$ Os dados expostos neste artigo foram extraídos das quatro entrevistas quinzenais e das fontes documentais (partitura de domínio público). As citações diretas da fala da participante serão apresentadas com recuo de 4 $\mathrm{cm}$ da margem esquerda, em itálico e indicando o dossiê que compila todos os dados coletados. Quando necessário, serão realizados destaques sublinhando partes da fala, de modo a enfatizar os elementos em discussão na análise dos dados.
} 


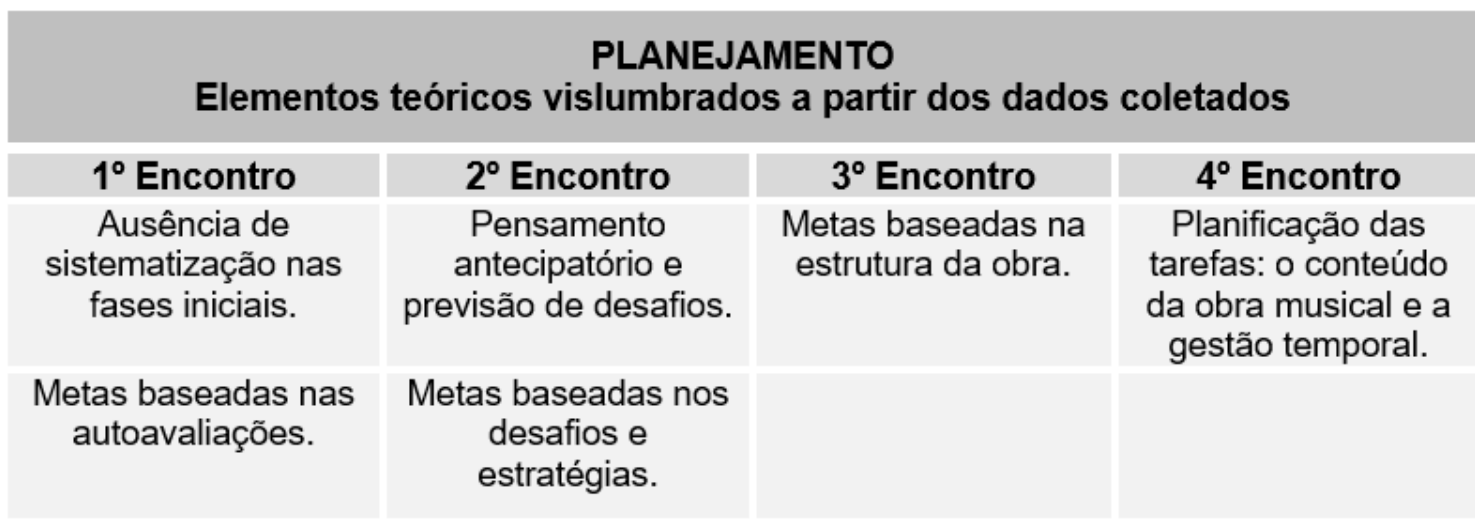

Figura 5: Elementos teóricos vislumbrados na fase de planejamento.

A planificação das tarefas incluiu o delineamento de metas de aprendizagem. Embora o início do ciclo de estudo tenha sido marcado por um planejamento com baixo nível de sistematização, conforme o processo avançou, essas fragilidades deram lugar à adoção de metas com características proximais (delimitação temporal), grau de complexidade variado e especificidade delimitada com base na estrutura e nos desafios da peça musical. "Proximidade", "dificuldade" e "especificidade" são elementos descritos por Schunk (2001, p. 132) como propriedades das metas. Os objetivos definidos por Ana ${ }^{6}$ basearam-se na autoavaliação contínua, nos desafios (enfrentados e previstos), nos recursos que dispunha (materiais ou não, a exemplo das estratégias) e na estrutura da obra musical (suas seções e exigências de realização).

No encontro um, a aspiração de avançar na leitura da peça e lidar com novos desafios musicais representaram a principal meta: "Pretendo seguir de onde eu não estou fazendo. [O início da obra] já está resolvido, é só treinar agora [...]. Eu já olhei ela de uma forma geral, mas eu não toquei tudo. Então, vou tentando tocar o trecho que não foi visto" (Dossiê Ana, entrevista do encontro 1, p. 19).

No encontro dois, Ana ampliou o detalhamento dos objetivos, sugerindo o trabalho com seções particulares da obra (com base nos desafios previstos envolvendo o idiomatismo instrumental e o andamento), o uso de estratégias específicas (como o estudo mental) e a delimitação temporal, que, embora não específica, é representativa do ponto de vista organizacional ("quero chegar aqui num periodo de tempo").

O meu foco agora são as duas últimas variantes (4 e 5), que vão dar mais trabalho. Meu objetivo agora é continuar o que já estou fazendo: sentar sem instrumento, imaginar a movimentação, o timpano e o xilofone, porque vai ser basicamente isso - vou usar duas baquetas de xilofone, uma de xilo aqui e uma de tímpano. E é muito rápido, então a

\footnotetext{
${ }^{6}$ Ana é o pseudônimo adotado em substituição ao nome da aluna participante deste estudo.
} 
minha intenção é começar devagar, mas sem instrumento, só na imaginação; quero chegar aqui /trecho específico do quinto movimentol num periodo de tempo (Dossiê Ana, entrevista do encontro 2, p. 25).

Bandura (1989, p. 1180) explica que "a capacidade de vislumbrar os resultados prováveis das ações prospectivas é outra maneira pela qual os mecanismos antecipatórios regulam a motivação e a ação humana". $\mathrm{O}$ autor reforça que uma função central dos processos cognitivos consiste na previsibilidade da ocorrência de eventos (em uma espécie de "simulação cognitiva"), oportunizando a criação de meios para exercer o controle sobre situações adversas. Neste sentido, dados coletados com Ana, no encontro dois, sugerem o uso do pensamento antecipatório com função diagnóstica, tomando como base a análise da tarefa e de seus desafios. Para Bandura (1986 apud Júnior; Winterstein, 2010, p. 6), a antecipação figura entre as cinco capacidades cognitivas básicas elencadas pela TSC, ao lado da simbolização, da autorregulação, da autoconsciência reflexiva e das competências vicariantes.

Eu não cheguei no trecho, mas aqui vai ser um probleminha, porque eu estava ouvindo alguém tocando a variação 4 e eu não estava conseguindo identificar o tempo certinho. Não parei pra tocar, mas analisando eu já achei meio complicadinho [...]. Eu acho que as duas últimas páginas vão dar mais trabalho em questão de leitura. Talvez não seja muito dificil, mas olhando agora me parece bem complicado (Dossiê Ana, entrevista do encontro 2, p. 23).

De acordo com Zimmerman e Cleary (2006), a planificação das tarefas concentra-se primordialmente na fase prévia dos processos autorregulatórios, ao lado da "definição das metas" e das "fontes de automotivação" para a realização. No caso de Ana, a seleção de "o que fazer" foi orientada, sobretudo, pelo conteúdo da obra musical e pela gestão do tempo de estudo. Embora tenham emergido tardiamente em seu discurso (encontro quatro), estas informações assumem relevância, visto que revelam traços autorregulatórios e apontam os critérios utilizados para a autoavaliação processual do desempenho com base no questionamento: "O que qualifica uma tarefa como cumprida, de modo a permitir o avanço no estudo?"

Nas 5 variantes [movimentos da obra] mais a introdução, eu não pensei em dividir por dias, mas realmente eu trabalhei seccionado: primeiro eu trabalhei a variante 1 , depois a 2 , depois a 3 , depois a $4 . .$. não que eu precisasse firmar, decorar

\footnotetext{
7 Original: "The ability to envision the likely outcomes of prospective actions is another way in which anticipatory mechanisms regulate human motivation and action".
} 
e tocar "de cabeça", não. Mas, assim, eu toquei e sei pra onde vai, eu sei que baqueta usar mais ou menos, eu fiz anotações, eu ouvi muito a pecca e fechei a [variante] 1 , ela está na minha cabeça, vamos para a 2; e assim foi... [...] [Agora], como seria para a última entrevista, eu não dediquei tempo só para a última variante [5] [...]. O maior tempo foi para ela, com certeza. Mas, depois que eu comecei a entender como ela [variante 5] deve ser executada, eu comecei a trabalhar [a obral de uma forma geral (Dossiê Ana, entrevista do encontro 4, p. 37).

\section{"Eu trabalhei com metas todo esse tempo": o automonitoramento do processo de estudo}

Azzi, Basqueira e Tourinho (2016, p. 107), em um ensaio sobre o ensino de música na perspectiva da TSC, apresentam o monitoramento como uma auto-observação sistemática e deliberada de aspectos públicos (sociais) e privados (pessoais) do desempenho em determinadas realizações, "como a compreensão de uma peça musical, seja através da leitura ou da percepção auditiva”. A figura a seguir apresenta a categorização dos dados da fase de monitoramento. 8

\begin{tabular}{|c|c|c|c|}
\hline \multicolumn{4}{|c|}{$\begin{array}{c}\text { MONITORAMENTO } \\
\text { Elementos teóricos vislumbrados a partir dos dados coletados }\end{array}$} \\
\hline $1^{\circ}$ Encontro & $2^{\circ}$ Encontro & $3^{\circ}$ Encontro & $4^{\circ}$ Encontro \\
\hline $\begin{array}{c}\text { Experiências } \\
\text { metacognitivas: } \\
\text { autoquestionamentos. }\end{array}$ & $\begin{array}{l}\text { Experiências e } \\
\text { conhecimentos } \\
\text { metacognitivos. }\end{array}$ & $\begin{array}{c}\text { Experiências } \\
\text { metacognitivas: } \\
\text { autoexplicação } \\
\text { verbalizada/pensar } \\
\text { alto. }\end{array}$ & $\begin{array}{c}\text { Experiências } \\
\text { metacognitivas: } \\
\text { verbalização das } \\
\text { estratégias/êxito } \\
\text { percebido. }\end{array}$ \\
\hline \multirow[t]{3}{*}{$\begin{array}{c}\text { Desafios: } \\
\text { especificidades da } \\
\text { percussão múltipla e } \\
\text { expectativas de } \\
\text { dificuldades. }\end{array}$} & $\begin{array}{l}\text { Conhecimentos } \\
\text { metacognitivos e } \\
\text { efetividade das } \\
\text { estratégias. }\end{array}$ & $\begin{array}{c}\text { Conhecimentos } \\
\text { metacognitivos e os } \\
\text { desafios observados. }\end{array}$ & $\begin{array}{l}\text { Conhecimentos } \\
\text { metacognitivos } \\
\text { procedimentais e } \\
\text { condicionais. }\end{array}$ \\
\hline & $\begin{array}{c}\text { Revisão das metas: } \\
\text { estratégias e } \\
\text { experiências } \\
\text { metacognitivas. }\end{array}$ & $\begin{array}{c}\text { Revisão das metas: } \\
\text { objetivos com base } \\
\text { no tempo e nos } \\
\text { desafios. }\end{array}$ & $\begin{array}{c}\text { Revisão das metas: } \\
\text { objetivos como } \\
\text { reguladores da } \\
\text { ação. }\end{array}$ \\
\hline & $\begin{array}{l}\text { Desafios: } \\
\text { especificidades da } \\
\text { percussão múltipla. }\end{array}$ & $\begin{array}{l}\text { Desafios percebidos: } \\
\text { a revisão da gestão } \\
\text { temporal e das } \\
\text { estratégias. }\end{array}$ & $\begin{array}{c}\text { Desafios } \\
\text { percebidos: } \\
\text { dificuldades } \\
\text { técnicas e musicais. }\end{array}$ \\
\hline
\end{tabular}

Figura 6: Elementos teóricos vislumbrados na fase de monitoramento.

\footnotetext{
${ }^{8}$ No tocante ao automonitoramento, ofereceremos uma ênfase exclusiva nas experiências metacognitivas e na observação e interpretação dos desafios de aprendizagem. Não obstante, os resultados sobre esta etapa do processo autorregulatório destacam outros elementos, a exemplo dos conhecimentos metacognitivos. Ver Veloso (2019).
} 
À luz da metacognição, o monitoramento dos comportamentos $\mathrm{e}$ realizações cognitivas envolve, dentre outros fatores, as experiências metacognitivas. Estes empreendimentos ocorrem quando há a ausência de compreensão sobre algo ou no entendimento súbito (epifania), tratando-se de experiências que estimulam o exercício intelectual altamente consciente (Livingston, 2003, p. 3-4). Segundo Schraw e Moshman (1995, p. 355), pesquisas apontam uma relação direta entre os aspectos metacognitivos e a acurácia do automonitoramento na aprendizagem. A análise dos dados deste estudo destacou as seguintes experiências metacognitivas (Figura 07):

\section{Fenômenos inerentes às experiências metacognitivas}

Autoquestionamento; perguntar a si mesmo.

Autoexplicação verbalizada; pensar alto.

Verbalização das estratégias e autopercepções de êxito

\section{Dados coletados: \\ "Unidades de verbalização"}

O que eu fiz de diferente hoje foi trocar a posição do bloco de madeira [instrumento]. Era para estar aqui, mas eu pensei "vou pôr as baquetas onde?" Aí eu coloquei as baquetas lá [indicando] (Dossiê Ana - entrevista do encontro 1, p. 16).

Eu estava tocando e fui identificando [as dificuldades], falei: "ah, vou anotar isso aqui porque se não vou esquecer" [ver figura $\overline{08}$ (entrevista do encontro 3, p. 28)

(...) tem vezes que eu coloco a baqueta lá e penso "não, tem que ser aqui ou em cima do xilofone". Então, se organizar aqui no múltiplo é realmente uma coisa muito difícil (Dossiê Ana entrevista do encontro 4, p. 38).

[Agora] como é a última variante, eu pensei "vou fazer ela inteira", e realmente foi mais efetivo (entrevista do encontro $4, p$. 34).

Figura 7: Fenômenos inerentes às experiências metacognitivas.

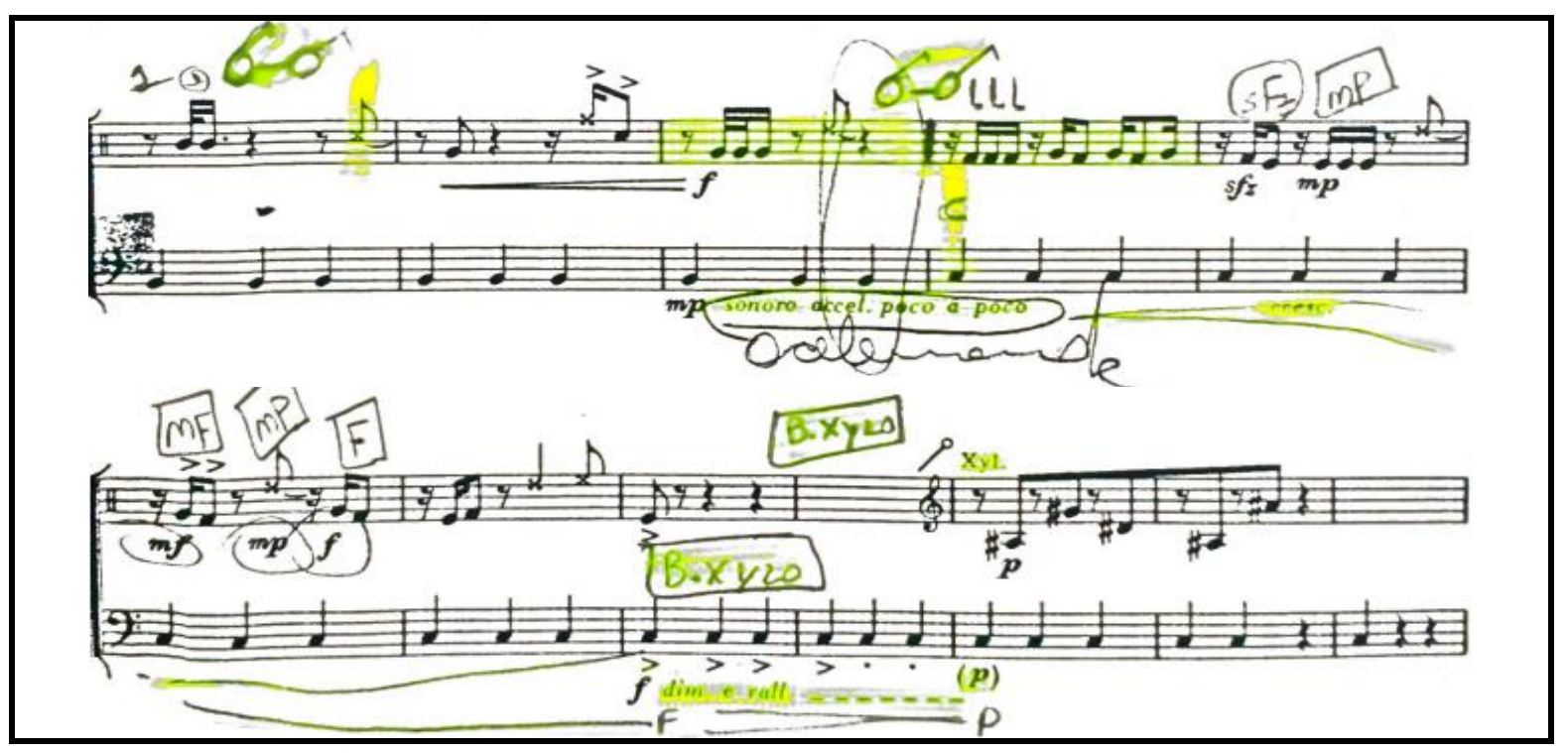

Figura 8: Trecho da obra Variantes, movimento 3 - passagem central (p. 4; sistema 3). Observar: destaques realizados - anotações e marcações na partitura. 
A observação e a interpretação dos desafios oferecem direcionamento às ações. Para Bandura (2017b, p. 131), os indivíduos "fazem coisas que lhes dão autossatisfação e autovalor", mesmo considerando os desafios a serem superados. Assim, "a forma como as pessoas veem as oportunidades e obstáculos em seu ambiente molda o curso que suas vidas levam”. Nessa dinâmica, as crenças de autoeficácia "determinam como os obstáculos e empecilhos são vistos" e superados. O contrário também é válido, considerando que a percepção dos desafios orienta a construção das autocrenças de capacidade. Estes elementos integram com os processos de monitoramento da aprendizagem e tornam-se centrais para a autorregulação.

Os resultados deste estudo possibilitaram a distinção entre duas classes de desafios: (1) os desafios percebidos, embasados na análise e reflexão sobre as experiências já vivenciadas; e (2) os desafios previstos, baseados na previsibilidade de eventos futuros representados por antecipação. Alguns aspectos relatados por Ana no início do processo de estudo podem ser compreendidos como preocupações da aprendizagem e estão associados tanto aos desafios percebidos (com destaque às variáveis específicas da percussão múltipla ${ }^{9}$ ) quanto aos desafios previstos. Um exemplo é a menção às ornamentações, mudanças de afinação no tímpano e trechos do xilofone, passagens qualificadas como complexas com base em uma visão geral da partitura.

Eu acho que você lidar com todos os instrumentos, tocar com baquetas adequadas para todos eles e fazer o som que você acha que precisa é o que está sendo mais difícil. [...] Ah, eu esqueci de falar do timpano, que está sendo um desafio também. [...] você acompanhar a melodia e preparar a pele [do timpano] bem certinho, fazer os glissandos e voltar... As alturas estão definidas bem certinhas, tem um sustenido até, depois ele volta [bequadro] [ver Figura 9]. Fica bonito, mas é difícil [...]. O [xilofone] tem bastante atividade depois. Não lembro se é muito difícil, mas vai ser bem trabalhado. Com mais presença, dirigindo o trecho (Dossiê Ana, entrevista do encontro 1, p. 17).

\footnotetext{
9 “A percussão múltipla é uma vertente interpretativa na qual um executante reúne diversos instrumentos para serem tocados alternada ou simultaneamente por necessidade imposta pela obra" (Morais; Stasi, 2010, p. 61).
} 


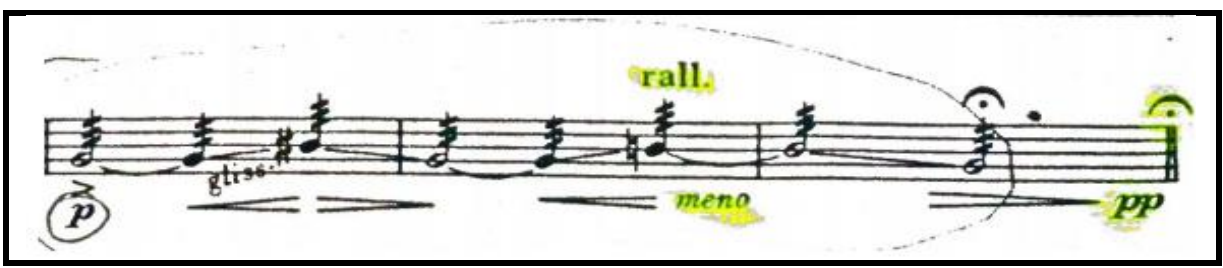

Figura 9: Trecho da obra Variantes, movimento 1 - passagem central (p. 5; sistema 5). Observar: glissandos e variações de altura (afinação) nos timpanos.

Nas fases finais da coleta de dados, as concepções de Ana acerca dos desafios enfrentados mostraram-se mais sólidas, possibilitando a distinção entre desafios técnicos e desafios de interpretação, com base em uma visão integral da obra. Neste momento, as percepções a respeito das dificuldades não se encontram mais no plano da previsão de desafios, mas no julgamento do desempenho. Inferências fruto de autoavaliações possibilitaram o reconhecimento das "dificuldades superadas" (como a leitura da obra em sua totalidade e a superação dos problemas técnicos primários), em contraste aos "desafios em processo de resolução", a exemplo das nuances de dinâmica, dos contrastes de andamento e dos ornamentos (glissandos).

[...] eu até fiz um levantamento dos pontos dificeis de forma geral. Tem muitas dificuldades que são técnicas, mas também de interpretação, os dois [elementos] entram nessa questão [das dificuldades]. Por exemplo: as dinâmicas continuam sendo um problema, principalmente na variação 1 [...]. O trabalho com a dinâmica eu sei que é uma coisa que preciso continuar, mas às vezes acabo não fazendo por conta de outras coisas. A velocidade de alguns trechos também é complicada, principalmente nas variantes 3 e 4 (por causa do xilofone, é bem difícil); sinto que tem melhorado, mas ainda continua uma dificuldade. Os glissandos são complicados; às vezes a questão é se perder: estou tocando aqui e, quando faço um glissando, eu meio que esqueço a partitura e, quando vou focar, eu já nem sei direito onde está (não só aqui [ver figura 10], mas em outros trechos também) (Dossiê Ana, entrevista do encontro 4, p. 34). 


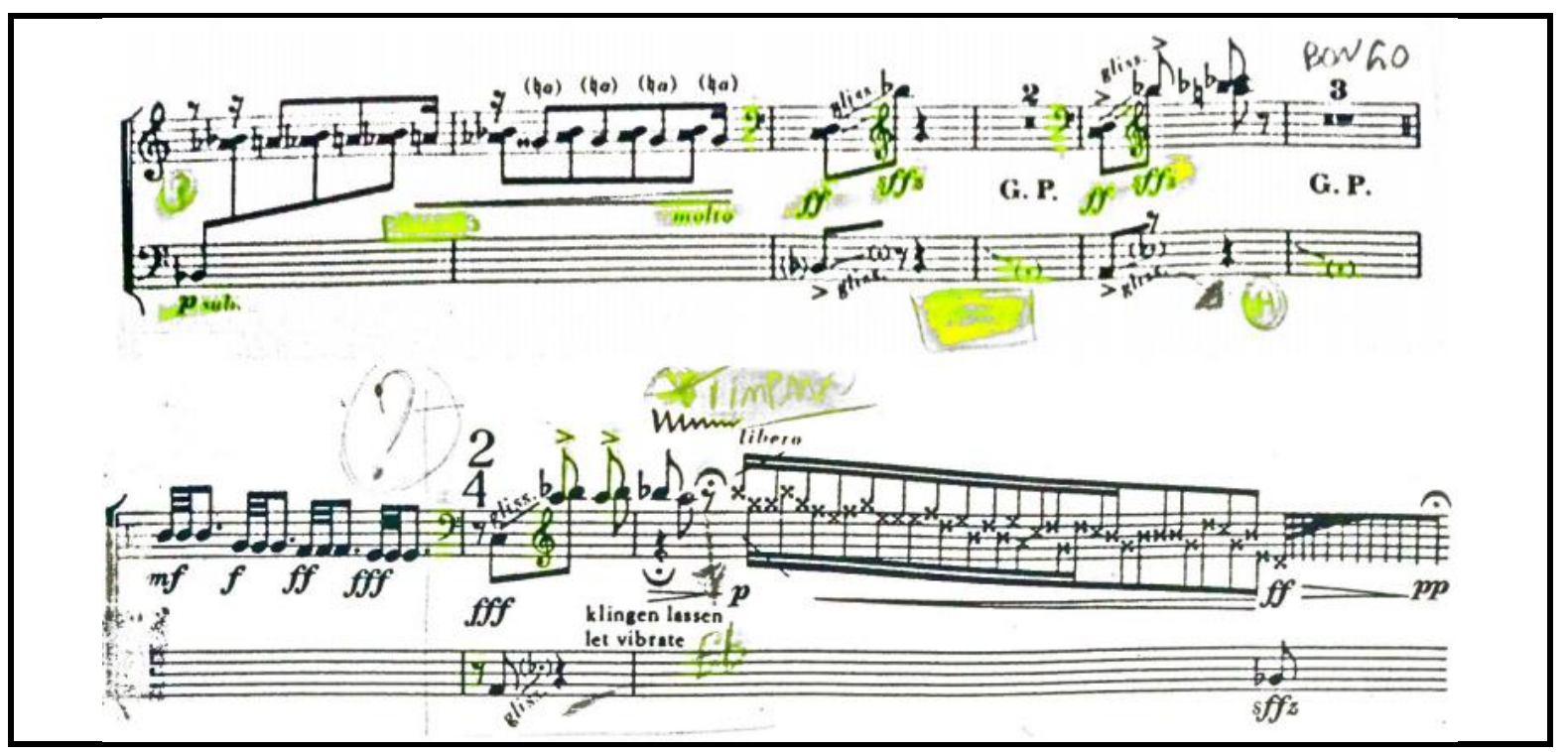

Figura 10: Variante 4 - passagem final (p. 5, sistema 5; p. 6, sistema 1) Observar: ornamentação - glissandos.

"Eu diria que a palavra do processo de tocar essa peça é o 'autoconhecimento": a autoavaliação da aprendizagem

Santos (2008, p. 123) esclarece que a autoavaliação, em situações de aprendizagem musical, "consiste na reflexão sobre a pertinência das estratégias frente às metas estipuladas, visando ao refinamento e aperfeiçoamento" da prática instrumental. Em outros termos, trata-se do julgamento pessoal acerca do próprio desempenho. A esse respeito, a análise dos dados - sintetizada na figura 11 - possibilitou a emergência de três categorias de resultados: (1) o feedback e as inferências autoavaliativas, (2) as atribuições de causalidade e (3) as inferências autorreativas.

\begin{tabular}{|c|c|c|c|}
\hline \multicolumn{4}{|c|}{$\begin{array}{l}\text { AUTOAVALIAÇÃO } \\
\text { Elementos teóricos vislumbrados a partir dos dados coletados }\end{array}$} \\
\hline $1^{\circ}$ Encontro & $2^{\circ}$ Encontro & $3^{\circ}$ Encontro & 4 Encontro \\
\hline $\begin{array}{c}\text { Feedback } \\
\text { autoavaliativo: } \\
\text { aspectos positivos. }\end{array}$ & $\begin{array}{c}\text { Feedback } \\
\text { autoavaliativo: } \\
\text { desafios de natureza } \\
\text { musical. }\end{array}$ & $\begin{array}{l}\text { Inferências } \\
\text { autovaliativas: } \\
\text { parâmetros } \\
\text { musicais. }\end{array}$ & $\begin{array}{c}\text { Feedback } \\
\text { autoavaliativo: } \\
\text { aspectos positivos e } \\
\text { negativos. }\end{array}$ \\
\hline \multirow[t]{2}{*}{$\begin{array}{l}\text { Atribuição de } \\
\text { causalidade: } \\
\text { especificidades do } \\
\text { domínio e } \\
\text { experiências } \\
\text { pessoais. }\end{array}$} & & & $\begin{array}{l}\text { Atribuições de } \\
\text { causalidade: metas, } \\
\text { estratégias e } \\
\text { esforços } \\
\text { despendidos. }\end{array}$ \\
\hline & & & $\begin{array}{c}\text { Inferências } \\
\text { autorreativas: ciclos } \\
\text { de estudo futuros. }\end{array}$ \\
\hline
\end{tabular}

Figura 11: Elementos teóricos vislumbrados na fase de autoavaliação. 


\section{O feedback e as inferências autoavaliativas}

$\mathrm{Na}$ fase inicial do estudo, as considerações apresentadas por Ana sugerem autoavaliações positivas acerca do seu desempenho. A estudante considerou os resultados preliminares (destacando o encaminhamento da leitura e a identificação dos trechos complexos da peça) e o nível de dificuldade da obra (que influiu nas expectativas de resultado e no valor atribuído à tarefa): "[...] acho que, para um primeiro momento, nos primeiros ensaios que eu tenho feito nesse trecho [introdução e variante 1], está saindo. Consegui identificar os trechos com maiores problemas, estou parcialmente satisfeita. Eu acho bacana, é uma trabalheira bem grande!" (Dossiê Ana, entrevista do encontro 1, p. 18).

$\mathrm{Na}$ fase central do estudo, os dados indicaram que, à medida que a construção da performance avançou, os julgamentos pessoais tornaram-se mais criteriosos e especificos, e o senso de autocrítica mais aguçado (abordando parâmetros musicais singulares). Isso reforça que a autoavaliação é guiada por elevados niveis de consciência reflexiva e considera tanto as exigências da tarefa quanto os resultados parciais obtidos. Desse modo, saber "o que fazer", saber "como fazer" e saber "o que se está fazendo" são conhecimentos de naturezas distintas, mas que se relacionam na autoavaliação.

[...] eu não estou nada satisfeita com as dinâmicas que eu tenho feito. Por exemplo, eu não acho que tenho conseguido diferenciar o "piano" de "pianissimo", e tem um "pianississimo" aqui na frente também, terrivel! Eu acho que está ficando muito igual. Essa é uma dificuldade que eu tenho identificado mais nos últimos dias. Quanto mais eu tenho tocado, mais eu tenho percebido que a coisa está muito semelhante. Eu não tenho ficado satisfeita. Aqui, por exemplo, na variação 3 [ver figura 12], eu comecei antes de ontem a pegar firme nela. Aqui é um trecho que hoje eu estava tocando e tentando fazer essas dinâmicas: aqui [pentagrama superior] ele exige um "sforzando", vai para o "mezzo-forte", vai para "forte" de novo, e aqui [pentagrama inferior] ele quer só um "crescendo". Então você não tem que atacar nada, você só tem que crescer enquanto a mão direita está [atuando ativamente] nos instrumentos. Esse é um trecho que, por enquanto, está sendo meio difícil (Dossiê Ana, entrevista do encontro 2, p. 22). 


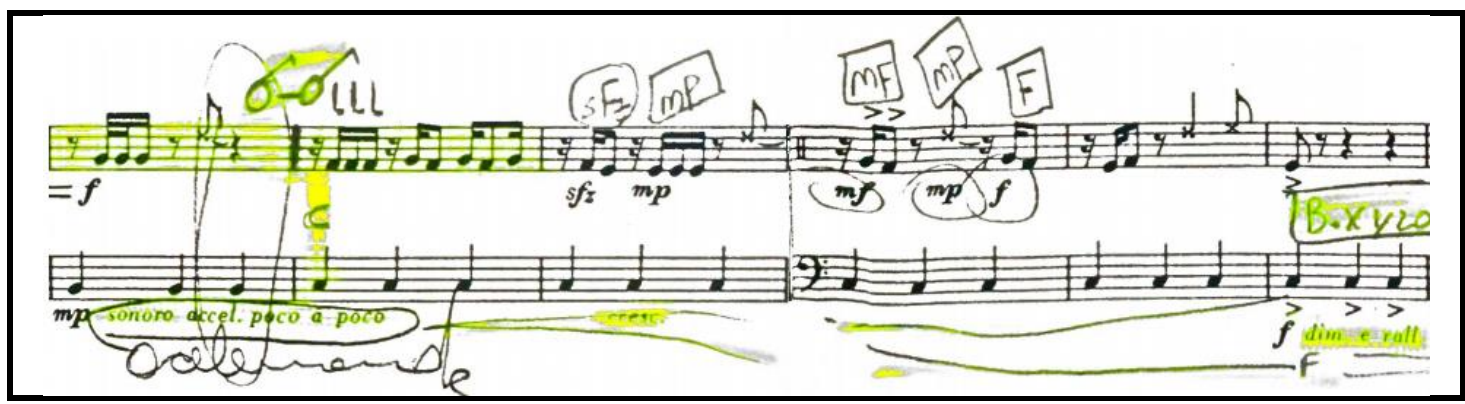

Figura 12: Trecho da obra Variantes, movimento 3 - passagem central (p. 4; sistema 3). Observar: variações de dinâmica e textura.

Com relação à fase final da coleta de dados, o relato a seguir apresenta a avaliação positiva dos resultados feita com base em critérios do domínio (especificidades musicais e técnicas da obra, considerando também o idiomatismo inerente à percussão múltipla). Nessa direção, notou-se um acurado senso crítico acerca do desempenho (com destaque aos ganhos e possiveis insucessos) em uma visão realista das dificuldades identificadas.

Acho que eu consegui me desenvolver bem com aquilo que a peça precisa. Não achei que eu fiquei aquém. Também não acho que está ótimo, mas, comparado à ideia que eu tinha, eu acho que eu consegui. Ela [a obra] não traz nada de absurdamente dificil [...]. [Mas] os problemas são inúmeros: tem problemas de dinâmica, problemas técnicos... mas, assim, eu gostei muito do desenvolvimento que eu tive a partir da peça (Dossiê Ana, entrevista do encontro 4, p. 36).

Segundo Portilho (2011, p. 116), "ao conhecer-se cada vez um pouco mais, a pessoa abre possibilidades de analisar as exigências próprias da tarefa e relacioná-las com a realidade que se apresenta". Desse modo, os individuos refletem sobre as informações, examinam as metas, atentam às novidades e familiaridades dos eventos observados e ponderam o nivel de exigência das tarefas, aspectos que elucidam a relevância do autoconhecimento para os processos autorregulatórios. Ana pontuou o autoconhecimento como um elemento central dos ganhos vivenciados a partir do estudo da obra. Os novos desafios criaram a necessidade do desenvolvimento de estratégias ("outras maneiras de estudar"), da sistematização dos recursos já utilizados e da adoção de condutas de estudo conhecidas, mas ainda não praticadas. Estes aspectos tendem a exercer impacto na formação musical de modo geral, influenciando a transferência de competências entre diferentes tarefas de um mesmo domínio (Cambridge, 2017 , p. 2), bem como a construção de conhecimentos declarativos (sobre o próprio funcionamento), procedimentais (sobre as estratégias pertinentes à cada desafio) e condicionais (sobre as especificidades das tarefas).

Essa questão de se autoavaliar realmente eu faço bastante e, por fazer, eu diria que a palavra do processo de tocar essa 
peça é o "autoconhecimento". Como eu falei, fiz coisas que eu nunca tinha feito, e que eu sabia que tinha que fazer, mas que eu não fazia porque menosprezava. Comecei a fazer e vi que surte efeito. Então, o autoconhecimento tocando peça de múltiplo, acho que foi o que eu mais ganhei e o que eu não tinha alcancado com outras pecas [...]. Aprendi muito comigo mesma assim, sabe. Se você for pensar, eu fiquei pouco no instrumento; mas me conhecendo, conhecendo a peça e outras maneiras de estudar que eu não fazia, foi muito enriquecedor. Agregou muito! (Dossiê Ana, entrevista do encontro 4, p. 38).

[O maior ganho] foi o autoconhecimento. Foi uma obra que me permitiu conhecer muito sobre o meu método de estudo. Provavelmente eu não tenha um método definido ainda; mas [este processo] contribuiu para [que eu saiba que] as coisas que eu não fazia (mas sei que tenho que fazer) são efetivas. Eu pude conhecer a mim mesma e uma forma de estudar que não é a que eu estava fazendo até então. Tecnicamente também foi bem enriquecedor, por trabalhar a percussão múltipla, trabalhar vários instrumentos (não tem como isso não ser um ganho pra gente) (Dossiê Ana, entrevista do encontro 4, p. 39).

Ao término do estudo da obra, as principais inferências autoavaliativas realizadas por Ana concentraram-se nas dificuldades vivenciadas em todo o processo. Como sugere a estudante (em uma visão otimista e positiva), a observância das dificuldades e falhas não deve ser qualificada como um fator negativo, visto que a ciência acerca dos insucessos pode orientar mudanças em direção à aprendizagem efetiva: "Conforme eu vou tocando, mais problemas e coisas que eu estou fazendo errado eu vou identificando, $o$ que é bom" (Dossiê Ana, entrevista do encontro 4, p. 39).

\section{Atribuições de causalidade}

Zimmerman e Cleary (2006, p. 62) - com base na teoria das atribuições causais (Weiner, 1986 apud Bandura, 1991) - esclarecem que, "depois que os estudantes realizam uma determinada tarefa, eles frequentemente avaliam e refletem cognitivamente sobre as causas percebidas de seu desempenho". ${ }^{10}$ As razões para determinados tipos de realização podem ser atribuídas à causas internas ao indivíduo (fatores controláveis, como esforços e estratégias) ou a causas externas (fatores incontroláveis, como sorte ou acaso). As atribuições avaliativas exercem influência nos processos autorregulatórios, especialmente pela interação com as crenças de autoeficácia, uma vez que estudantes com elevado senso de eficácia pessoal tendem a atribuir as falhas no processo de estudo a fatores possiveis de serem controlados, ao passo que estudantes com baixas

\footnotetext{
${ }^{10}$ Original: "[...] after students perform a task or an activity, they will often evaluate or reflect cognitively on the perceived causes of that performance".
} 
crenças de autoeficácia atribuem seus fracassos a fatores incontroláveis (Zimmerman; Cleary, 2006, p. 62).

No início do processo de estudo, Ana associou os desafios vivenciados a dois fatores: (1) às particularidades do dominio da percussão múltipla, em concordância com o exposto por Zimmerman (2000) a respeito dos critérios do dominio, e (2) à pouca experiência pessoal com esta modalidade instrumental, fator explicado por Austin e colaboradores (2006, p. 227-229) como habilidades pessoais no que toca às atribuições de causa para o desempenho instrumental.

[...] não há um costume [com a percussão múltipla], né? Não é como a marimba, que você tem quatro baquetas e se resolve ali. Não, é uma baqueta para cada coisa e, nessa movimentação, você não sabe onde deixa a baqueta, se é aqui, para facilitar pra cá, ou se é pra lá, sabe? É uma coisa a se pensar ainda. Mas é realmente isso, parece que é a falta de prática com a percussão múltipla; você dar conta de vários instrumentos diferentes [...] (Dossiê Ana, entrevista do encontro 1, p. 18).

Austin e colaboradores (2006) concebem os esforços despendidos (aspectos internos ao indivíduo e, portanto, controláveis) como critérios atribucionais. Ao término do ciclo de estudo, Ana frisou as metas, estratégias e esforços investidos, reforçando os bons resultados obtidos (atribuições aos êxitos): “[...] além das metas, as estratégias que eu usei para alcançar essas metas me fizeram conseguir ler a peça. Deu para alcançar los objetivos] justamente porque eu seccionei a peça e levantei as estratégias" (Dossiê Ana, entrevista do encontro 4, p. 37), "[...] eu acho que as metas e as estratégias que eu mesma defini surtiram efeito" (Dossiê Ana, entrevista do encontro 4, p. 39).

O relato apresentado na sequência descreve atribuições aos insucessos (dificuldades de movimentação e ausência de consciência gestual atribuídas a defasagens cognitivas de atenção e memorização) e aos êxitos (competências organizacionais relativas às habilidades pessoais, esforços despendidos e critérios do dominio) (Zimmerman, 2000; Austin et al., 2006). Ambos os aspectos (êxitos e insucessos) estiveram relacionados às particularidades do domínio da percussão múltipla.

Mas, ainda assim, o problema [da movimentação] continua persistindo, porque às vezes eu acabo não dando atenção, não tá na memória que, naquele trecho, eu tenho que trazer baqueta pra cá ou tem que levar pra lá. Mas também tem alguns aspectos que amadureceram (num sentido positivo). Por exemplo: eu sinto que agora eu tenho organizado, eu consigo entender que a baqueta está aqui, o woodblock está ali, o triângulo está lá, assim, é mais rápido de montar. Mas, ainda assim, a questão estrutural de você se movimentar, de pegar baqueta e de levar lá, e não aqui, é bem dificil. Tem que 
estudar [essa movimentação] (Dossiê Ana, entrevista do encontro 4, p. 38).

Encerrando estas considerações, destacamos um depoimento oferecido por Ana ao término da coleta de dados, no qual a aluna apresentou a quantidade de tempo destinado para o estudo como justificativa para algumas fragilidades da execução da peça, estabelecendo uma relação de causa e efeito entre o tempo investido e os resultados obtidos: "Minha própria expectativa era de ter me dedicado mais à peça [...]. Acho que é uma grande falha. [A peça] poderia estar melhor, um pouco mais firme, tem trechos que eu fico insegura [...]. Acho que isso é consequência do tempo que eu deixei de destinar para ela" (Dossiê Ana, entrevista do encontro 4, p. 39). Para Austin e colaboradores (2006), estes fatores são justificados teoricamente como critérios autoavaliativos baseados nos esforços despendidos.

\section{Inferências autorreativas}

Para Bandura (1991, p. 253), as autoavaliações possibilitam reações pessoais corretivas (autorreações) por meio da comparação do desempenho com objetivos e padrões pessoais. Polydoro e Azzi (2008, p. 156) explicam que a maior parte do comportamento é regulado "por consequências autoavaliativas, na forma de autossatisfação, autoinsatisfação e autocrítica". $\mathrm{Na}$ mesma direção, Bandura (1989, p. 1180) elucida que "as pessoas buscam autossatisfação cumprindo metas valorizadas e são estimuladas a intensificar seus esforços pelo descontentamento com desempenhos abaixo do padrão". ${ }^{11}$ Portanto, iniciativas direcionadas aos ajustes motivados pelas autoavaliações são a centralidade da autorreação nos processos autorregulatórios.

À medida que o estudo da obra se aproximou do fim, as inferências avaliativas realizadas por Ana apontaram para a replicação de condutas em futuras situações de aprendizagem, o que reforça o viés cíclico da autorregulação: "[...] coisas que eu sei que deram certo, se eu levar pra frente e aplicar em outras peças, vai surtir o mesmo efeito" (Dossiê Ana, entrevista do encontro 4, p. 38). Quando convidada a simular um recomeço do processo de estudo (levando em consideração as experiências angariadas), Ana não manifestou a intenção de realizar mudanças incisivas, mas de reforçar um aspecto que, segundo ela, influenciou direta e positivamente os êxitos vivenciados no trabalho com a obra: a definição e a manutenção das metas.

Eu sei que agora eu começaria a estudar de uma maneira diferente. Eu acho que eu não mudaria, eu só amadureceria a ideia das metas. Metas pessoais com a peça, porque eu acho que foi bem válido e foi o que fez eu ler a peça inteira. Eu acho

\footnotetext{
11 Original: "People seek self-satisfactions from fulfilling valued goals and are prompted to intensify their efforts by discontent with substandard performances".
} 
que isso eu amadureceria, trabalharia ainda mais com isso, fortaleceria isso (Dossiê Ana, entrevista do encontro 4, p. 39).

\section{CONCLUSÕES}

Adotando como marco teórico a autorregulação à luz do paradigma sociocognitivo, este trabalho foi orientado à investigação dos elementos subjacentes ao planejamento, monitoramento e avaliação da aprendizagem instrumental. Durante o processo de aprendizagem acompanhado neste estudo de caso, o planejamento das realizações foi marcado pelo delineamento de metas de aprendizagem com características proximais, complexidade variada e especificidade delimitada. Ao lado das metas, a planificação das tarefas foi norteada majoritariamente pelo conteúdo e estrutura da obra musical, pelos desafios previstos e pela gestão do tempo de estudo. No monitoramento, exerceram influência os conhecimentos e as experiências metacognitivas - a exemplo das condutas de autoquestionamento (perguntar a si mesmo) e da autoexplicação verbalizada (pensar alto) -, além da revisão das metas e estratégias e da observação e interpretação dos desafios, tanto os previstos (representados mentalmente por antecipação) quanto os vivenciados.

A respeito da autoavaliação, os dados possibilitaram a emersão de três categorias: (I) $O$ feedback $e$ as inferências autoavaliativas, que se tornaram mais específicos e baseados na autocrítica ao longo do processo de aprendizagem, assumindo o autoconhecimento como a principal conquista deste ciclo de estudo; (II) as atribuições de causalidade consideraram especialmente a relação entre as metas adotadas e os êxitos obtidos; as dificuldades vivenciadas foram atribuídas às particularidades da percussão múltipla (critérios do domínio), às habilidades pessoais e ao tempo e esforços despendidos; por fim, (III) as inferências autorreativas consistiram na intenção de replicar condutas exitosas em situações futuras e reforçar a manutenção das metas pessoais.

Em resumo, os dados aqui expostos sugerem a valorização dos processos motivacionais; o planejamento das tarefas, a gestão do tempo e o investimento de esforços em função das necessidades do estudo; o delineamento de metas, de modo a organizar e direcionar a aprendizagem; o engajamento em nível cognitivo e metacognitivo, possibilitando a reflexão e o controle dos pensamentos e ações; a adoção de uma diversidade de estratégias de estudo; dentre outros aspectos. Estes resultados salientam elementos que, alinhados aos estudos sobre autorregulação e aprendizagem musical, possibilitaram a expansão da assertiva já contestada por Barry e Hallam (2002): “A prática leva à perfeição". Neste caso, podemos considerar que a prática consciente, reflexiva e autônoma (engajada cognitiva e motivacionalmente) conduz ao êxito da aprendizagem instrumental. 


\section{REFERENCIAS}

ARAÚJO, Marcos. O desenvolvimento de um questionário de comportamentos autorreguladores da prática musical em intérpretes. Revista Música Hodie, Goiânia, v. 15, n. 1, p. 145-152, 2015.

AUSTIN, James; RENWICK, James; MCPHERSON, Gary. Developing motivation. In: MCPHERSON, G. (Org.). The child as musician: a handbook of musical development. New York: Oxford University Press, 2006. p. 213-238.

AZZI, Roberta Gurgel. Autorregulação em música: discussão à luz da teoria social cognitiva. Revista Modus, Belo Horizonte, v. 10, n. 17, p. 9-19, 2015.

AZZI, Roberta Gurgel; BASQUEIRA, Ana Paula; TOURINHO, Ana Cristina Gama dos Santos Tourinho. Ensino na perspectiva da Teoria Social Cognitiva: discussões iniciais a partir do ensino de música. Revista da Abem, v. 24, n. 36, p. 105-115, 2016.

BANDURA, Albert. A crescente primazia da agência humana na adaptação e mudança na era eletrônica. In: BANDURA, A.; AZZI, R. G. (Org.). Teoria social cognitiva: diversos enfoques. Campinas: Mercado de Letras, 2017b. p. 83-128.

BANDURA, Albert. Social cognitive theory of self-regulation. Organizational behavior and human decision processes, v. 50, p. 248-287, 1991.

BANDURA, Albert. Human Agency in Social Cognitive Theory. American Psychologist, 44, p. 1175-1184, 1989.

BARDIN, Laurence. Análise de conteúdo. São Paulo: Edições 70, 2011.

BARRY, Nancy; HALLAM, Susan. Practice. In: PARNCUTT, R.; MCPHERSON, G. E. (Eds.). The science and psychology of music performance. Oxford: University Press, 2002. p. 151-165.

CAMBRIDGE. Metacognition. Cambridge Assessment, 2017. Disponível em: https: / www.cambridgeinternational.org/Images / 272307metacognition.pdf.

CAVALCANTI, Célia Regina Pires. Prática instrumental e autorregulação da aprendizagem: um estudo sobre as crenças de autoeficácia de músicos instrumentistas. In: ARAÚJO, R. C.; RAMOS, D. (Orgs.). Estudos sobre motivação e emoção em Cognição Musical. Curitiba: UFPR, 2015. p. 189-211.

FERIGATO, Arícia; FREIRE, Ricardo Dourado. Análise de conteúdo no contexto da pesquisa em performance musical: a metacogninção como objeto de análise. Percepta - Revista de Cognição Musical, v. 2, n. 2, p. 111124, 2015. 
FLAVELL, John. Metacognition and cognitive monitoring: a new area of cognitve-developmental inquiry. American Psychologist, v. 34, n. 10, p. 906$911,1979$.

JÚNIOR, Rubens Venditti; WINTERSTEIN, Pedro José. Ensaios sobre a Teoria Social Cognitiva de Albert Bandura. Parte II: reciprocidade triádica, modelação e capacidades humanas fundamentais. Lecturas: Educación física y deportes, Buenos Aires, n. 145, p. 1-11, 2010.

LIVINGSTON, Jennifer. Metacognition: an overview. Education Resources Information Center, v. 9/97, p. 2-7, 2003.

MCPHERSON, Gary; NIELSEN, Siw; RENWICK, James. Self-Regulation Interventions and the Development of Music Expertise. In: BEMBENUTTY, H.; CLEARLY, T. J.; KITSANTAS, A. (Eds). Applicattions of self-regulated learning across diverse disciplines. Charlott, NC: Information Age Publishing, 2013. p. 355-382.

MORAIS, Ronan Gil; STASI, Carlos. Múltiplas faces: surgimento, contextualização histórica e características da percussão múltipla. Opus, v. 16, n. 2, p. 61-79, 2010.

POLYDORO, Soely Aparecida Jorge; AZZI, Roberta Gurgel. Autorregulação: aspectos introdutórios. In: BANDURA, A.; AZZI, R. G.; POLYDORO, S. (Orgs.). Teoria Social Cognitiva: conceitos básicos. Porto Alegre: Artmed, 2008. p. 149-164.

PORTILHO, E. M. L. Como se aprende? Estratégias, estilos e metacognição. 2. ed. Rio de Janeiro: Wak, 2011.

PORTILHO, Evelise Maria Labatut; DREHER, Simone Souza. Categorias metacognitivas como subsídio à prática pedagógica. Educação e Pesquisa, São Paulo, v. 38, n. 1, p. 181-196, 2012.

SANTOS, Regina Antunes Teixeira. Modos de pensamentos reflexivos implícitos nos fatores de aperfeiçoamento da prática musical. Música em Perspectiva, v. 1, n. 2, p. 113-130, 2008.

SCHRAW, Gregory; MOSHMAN, David. Metacognitive theories. Educational Psychology Review, v. 7, n. 4, p. 351-371, 1995.

SCHUNK, Dale. Teoria Social Cognitiva na educação: contribuições e direções futuras. In: SEMINÁRIO INTERNACIONAL TEORIA SOCIAL COGNITIVA EM DEBATE, 1., 2015, Campinas. Anais [...]. Campinas: Unicamp, 2015. p. 61-76.

SCHUNK, Dale. Social cognitive theory and self-regulated learning. In: ZIMMERMAN, B.; SCHUNK, D. (Orgs.). Self-regulated learning and academic achievement: theoretical perspectives. Mawah, NJ: Erlbaum, 2001. p. 125152 . 
YIN, Robert. Estudo de caso. Planejamento e métodos. Porto Alegre: Bookman, 2005.

ZIMMERMAN, Barry. Attaining self-regulation: a social cognitive perspective. In: BOEKAERTS, M.; PINTRICH, P.; ZEIDNER, M. (Eds.). Handbook of selfregulation. New York: Academic Press, 2000. p. 13-39.

ZIMMERMAN, Barry; RISEMBERG, Rafael. Self-regulatory dimensions of academic learning and motivation. In: PHYE, G. D. Handbook of academic learning: construction of knowledge. San Diego: Academic Press, 1997. p. 105-125.

ZIMMERMAN, Barry; CLEARY, Timothy. Adolescents development of personal agency: the role of self-efficacy beliefs and self-regulatory skill. In: PAJARES, F.; URDAN, T. (Eds.). Self-efficay beliefs of adolescents. Greenwich, CT: Information Age Publishing, 2006. p. 45-69. 
Flávio Veloso é professor auxiliar do curso de Licenciatura em Música da Pontifícia Universidade Católica do Paraná (PUC-PR) e professor colaborador do curso de Licenciatura em Música da Universidade Estadual do Paraná (Unespar/Embap). É mestre em Música (Cognição/Educação Musical) e graduado em Música (Licenciatura) pela Universidade Federal do Paraná (UFPR). Atualmente cursa o Bacharelado em Instrumento/Percussão na Escola de Música e Belas Artes do Paraná (Unespar/Embap). Foi bolsista do CNPq na modalidade IC (2014-2015) e bolsista de mestrado da Capes (2017-2019). É membro do grupo de pesquisa Processos Formativos e Cognitivos em Educação Musical (PROFCEM/UFPR); professor/pesquisador associado à Associação Brasileira de Cognição e Artes Musicais ( $A B C M)$, à Associação Brasileira de Educação Musical (Abem) e à Associação Nacional de Pesquisa e Pós-graduação em música (Anppom). Sua produção artística concentra-se no âmbito da música de câmara (Duo Sabel Veloso) e no contexto orquestral (Osembap). No momento, atua na docência (PUC-PR; UNESPAR/EMBAP) e na produção de materiais didáticos para o ensino superior (graduação e pós-graduação), junto ao Centro Universitário Internacional Uninter. Seus interesses de formação e atuação concentram-se nas áreas da educação musical, cognição musical, performance musical, percussão sinfônica. https://orcid.org/0000-0003-4083-6550

Rosane Araújo é Pós-doutora em Educação Musical pela Universidade de Bolonha (Itália), doutora em Música pela Universidade Federal do Rio Grande do Sul. Ocupa o cargo de professora associada na Universidade Federal do Paraná, Departamento de Artes, onde atua nos cursos de Graduação e Pós-Graduação em Música (mestrado e doutorado); é coordenadora do Programa de Pós-Graduação em Música da UFPR, bolsista de produtividade em pesquisa pelo Conselho Nacional de Desenvolvimento Científico e Tecnológico (CNPq) e vice-presidente da Associação Brasileira de Cognição e Artes Musicais. Desde 2009, é líder do grupo de pesquisa Processos Formativos e Cognitivos em Educação Musical (PROFCEM), no CNPq. https://orcid.org/0000-0002-3676-1042 